Session \#\#\#

\title{
The Significance of Behavior Type on Web Information Retrieval and Academic Success
}

\author{
Chanel T. THOMAS, Chang Soo NAM, and Tonya L. SMITH- \\ JACKSON
}

\author{
Virginia Polytechnic Institute and State University \\ Blacksburg, Virginia, USA 24061
}

\begin{abstract}
This research tests the relationship between Type A/B Behavior, information retrieval on the World Wide Web, and on academic success of college level students. The participants included 26 Industrial \& Systems Engineering students at Virginia Polytechnic Institute \& State University. The Behavior Type of the students was determined by means of a 25 item checklist based upon attributes identified by Friedman and Rosenman (1974) ${ }^{1}$. Quality cumulative average data were collected on a participant demographic sheet. The information seeking behavior strategies examined included direct address, subject directories and search engines. The results of the study revealed that there is a significant relationship between Behavior Type and quality cumulative average. Type A students had higher academic achievement then Type B students. In contrast, Type B students appeared to exceed their Type A counterparts in search tasks on the Web. A combination of developing pedagogies that are conducive to the learning styles of Type A individuals and designing Web pages targeted towards individuals using search engines will support information literacy in Engineering Students. Future implications include researching the effects of Behavior Type on particular areas of study such as Engineering and Mathematics vs. English and History.
\end{abstract}

\section{Introduction}

Information literacy refers to a "person's ability to access and understand a variety of information resources (Lenox and Walker, 1993; p. 314) ${ }^{2}$." Information literacy in Engineering is important for both academic and career success. Web and database searches are common activities associated with information retrieval, and information literacy reflects an individual's knowledge and skills associated with information retrieval. Students are relying on the World Wide Web (WWW) more frequently to obtain information. Given students' growing dependence on the Internet to access credible information associated with research and independent learning, it is important that the Web be ergonomically designed, as is the case for any other tool used to perform a task. In addition, it is important to integrate the new demands for information literacy into the Engineering curriculum, but this integration will not be successful unless educators are aware of two important factors that can potentially undermine search success -- interface design and human attributes (students). 
Maddux, Johnson and Willis $(1997)^{3}$ stated, that like any other tool, a computer may be misused. As of today, Web pages are developed by anyone who has the capability to do so. There are few standards or guidelines that must be followed to publish a page. This simply means that there are a vast number of authors on the Internet. With this in mind, it becomes even more important to educate Web publishers responsible for designing and ensure that they not only appeal to the user's needs but also to the user's behavioral styles. According to Amichai-Hamburger (2002) ${ }^{4}$, Web designers need to find out what information is required of people and how it may be restructured to incorporate individual characteristics and still relay the proper information. The Web searching tactics implemented by users of the Internet all over the world vary, however, little is known about why this variation exists.

Amichai-Hamburger $(2002)^{4}$ divided Internet users into four separate categories: those who use and enjoy, those who use only email, those who use a limited number of services, and those who use a wider range of services. He concluded that most people who do not use the Internet do so merely because they chose not to. For this reason, it is just as important to study non-users as those who use the Internet. In addition to cognitive style and Behavior Type, Amichai-Hamburger, Y. $(2002)^{4}$ suggested that Web designers look at individual traits such as need for closure, innovation, locus of control, attachment, profile of interests, and risk taking. Within each of these personality traits lies two extremes, which dictate search techniques. Hyperlinks are distracting for people with a high need for closure, while they are essential for those with low needs for closure. Also issues concerning whether it is essential to frequently make changes to sites must be considered. Innovators appeal to sites that change frequently, while conformists are easily distracted by sites that are constantly being changed. Amichai-Hamburger $(2002)^{4}$ concluded that individual surfers of the Web should have the opportunity to take tests that would reveal their personality types, at which time a specific site may recommend directions for searching.

This research was designed to establish connections between information seeking behavior on the Web and Behavior Type and, as a secondary measure, the relationship between Behavior Type and academic success. Type A Behavior traits may be one of the human attributes that may undermine search success. Type A and B Behavior Types were examined. According to Jenkins, Zyzanski, and Rosenman (1979) ${ }^{5}$, Type A Behavior is a result of a constant battle of an individual's surrounding barriers. Individuals characterized as displaying Type A Behavior are extremely competitive, aggressive, challenged by responsibility, and frequently under the pressure of time. On the other hand, Type B individuals are mellow, unhurried, and less goal-oriented than Type A individuals (Jenkins, Zyzanski, and Rosenman 1979) ${ }^{5}$. Kliewer, Lepore and Evans (1990) ${ }^{6}$ found that Type B female students, compared to all others, have the most difficulty recovering from failure in an academic environment and have more negative opinions of their own performance. In addition to Behavior Type, it was found that females take longer to recover from failure due to lack of ability and not motivation. Therefore, Type B females may be at risk when demanding cognitive tasks are performed and will have little to no preference for challenge. A study conducted by Perry and Tunna $(1988)^{7}$ found that Type A students benefited from contingent feedback from professors, but were not necessarily disabled as a result of non-contingent feedback. Type A students felt more of a responsibility for their own academic success and, therefore, did not directly depend on instructors for increased performance. Negative feedback and failure led Type A students to become more diligent 
and strive for total control of the situation, while Type B students were more adversely affected by outside influences.

Relatively little research has been done to connect Behavior Type with search strategies on the Web and academic success. The differences between Type A and Type B individuals occur in values, style of speech, gestures, and style of thought. These differences may manifest as differences in search success, search strategies, and overall academic performance in Engineering.

\section{Hypotheses}

After conducting a literature review of the material available, the following hypotheses were developed:

1. Type A individuals will demonstrate higher achievement levels than Type B individuals.

2. Type A individuals will perform better on search tasks than Type B individuals.

\section{Methodology}

Participants: The participants included 26 Industrial and Systems Engineering students at Virginia Tech. The students were all undergraduate students ranging from second year to senior year students. Of the 26 students, 6 were female and 19 were male. Students were informed of the study by way of email through a condensed listserv. The participants were paid $\$ 7$ per hour as compensation for their time. Information on the participants Quality Cumulative Average (QCA) and gender were collected from a short demographic questionnaire. The QCA identified for the participants was self-reported and, therefore, has the potential to be inaccurate and/or inconsistent with transcripts maintained by the University.

Behavior Type: $\quad$ Behavior Type, was operationalized as scores reflecting degree of Type A trait reported by each participant. Participants' Behavior Type was determined using a 25-question checklist developed based upon characteristics identified by Friedman and Rosenman (1974) ${ }^{1}$.

\section{Procedure}

Information seeking behavior on the Web was recorded using two computer programs, Webmonitor \& Camtasia, and free response from the participant. Both Webmonitor and Camtasia recorded screenshots while the participant searched the Web. These screenshots were used to determine which search strategies were most frequently used and which key words were used for search engines and subject directories. The information seeking portion of the study required the participant to find the answer to 32 independent questions on the Web, regardless of whether the answer was known prior to searching. For each question the participant was given a sheet on which to write their initial search strategy upon reading the question. After writing down the initial search strategy, the participant searched the Web for the answer to the question. The students were given a five-minute time limit to locate the information for each question on the Web. Upon locating the answer, the participant wrote down the URL where the information was located along with any changes from their initial search strategy. 


\section{Results}

For the Type A behavioral measure, the total number of questions answered with a response of "yes" were tallied and the result was the participant's score. Since the checklist was not a standardized psychometric instrument, no normalized scores exist. Thus, the categorization was based upon a tendency toward Type A Behavior, which was indicated on a continuous scale at the higher end, while Type B tendencies manifest as lower scores on the same continuous scale. The sample mean was $11.09(S D=4.06)$. The total number of questions answered with a response of "yes" were tallied and the result was the participant's score. A mean was then scored from the results of all of the students to determine cut off points for Type A and B Behavior $[M=11.09, S D=4.06]$. Students having scores at the mean and above were labeled Type A $[M=14.53, S D=2.13]$, while those below the mean were labeled Type B $[M=8.06, S D=2.66]$.

Information seeking behavior was operationalized as search success, the number of answers located on the Internet within the allowable time frame by the participant. The total number of answers located successfully was totaled for each participant to determine the percentage of questions answered correctly. Initial search strategy was operationalized as the initial method used to locate information on the Web as reported by the participant. Changes in search strategy were likely to occur if the initial search strategy proved unsuccessful. The initial search strategy used was measured as having one of two properties. The individual either used a search engine for the initial search strategy or a non-search engine. The total number of times an individual used a search engine was reported upon completion of the searching component of the study.

Pearson-r correlations were conducted to detect relationships and significant differences among Behavior Type (treating the scores as a continuous variable), QCA, success rate, and initial search strategy. A positive correlation was found between Behavior Type and QCA $[r(29)=.54, p$ $<.01]$. Behavior Type and success rate were found to be negatively correlated $[r(26)=-0.60, p<$ $.001]$. There was no correlation between Behavior Type and initial search strategy. Success rate and initial search strategy were not significantly correlated. T-tests were conducted to identify significance amongst Type A and B Behavior with QCA and search success using the mean split described above to create dichotomous variables. A significant difference was found between Type A and B Behavior and QCA $[t(29)=-3.78, p<.01]$, revealing that Type A students had higher QCAs compared to Type B students. Graphs of the comparisons of Type A and B Behavior for search success and QCA are found in Figures 1 and 2 respectively. No other significant differences were identified. 


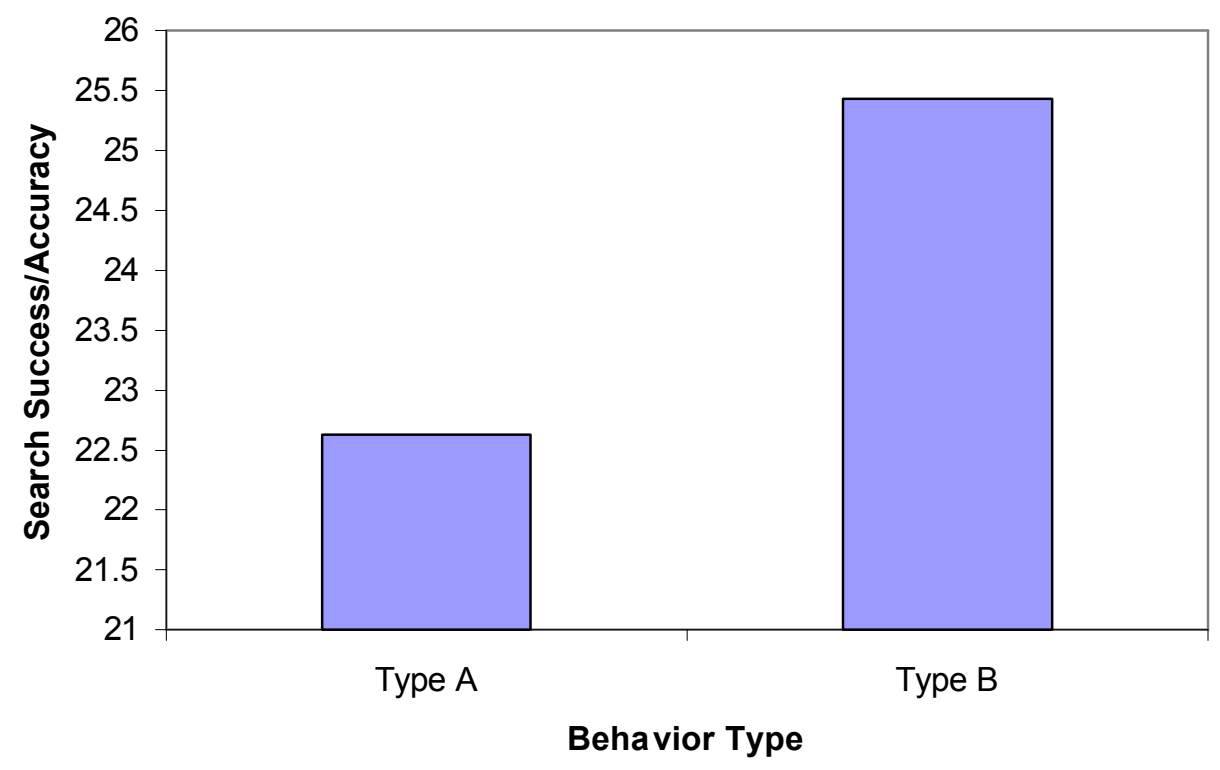

Figure 1. Search Success and Behavior Type

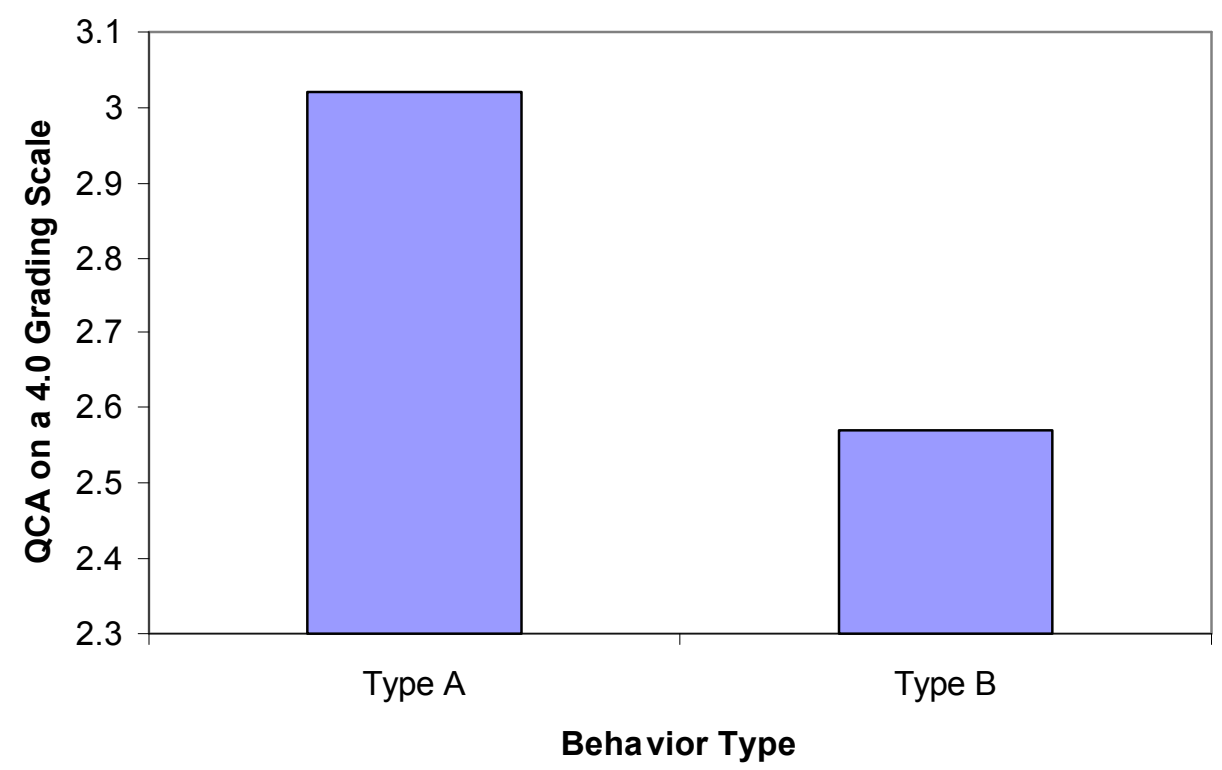

Figure 2. QCA and Behavior Type

\section{Discussion and Conclusions}

The purpose of this research was to explore the relationship between Type A/B Behavior, search success, and academic success. Increasing Behavior Type scores were associated with higher QCAs, thus Type A students tended to demonstrate higher achievement. In contrast, a significant 
negative correlation between Behavior Type and success rate indicated that Type A students were less successful at finding information on the Web. Interestingly, success rate and the initial search strategy were not significantly related. These finding suggest that more educational research should be done to understand how to accommodate Behavioral Types to support the development of information literacy.

Since there was a positive correlation between QCA and Behavior Type, it becomes necessary to reconsider the current methodology for instructing students in higher education. Prior to the first day of class professors usually have completed the lesson plan and have begun designing the test structure. This is all completed without any prior knowledge of the students' Behavior Type or teaching techniques that are most conducive to the students' learning styles or preferences. Some professors are well aware that multiple learning styles exist in the classroom, but are unaware of how to design their pedagogy to account for the differences (Anderson and Reed, 1998) ${ }^{8}$. Professors could prove more successful by assessing students early in the semester and modifying their pedagogy as needed. This information would then be used to restructure lesson plans and the format of independent tests to appeal to students' learning patterns. Instead of using a teaching method that favors one type of student, professors could incorporate multiple teaching strategies and perhaps offer more than one version of each test. This may require a substantial increase in the amount of work required of professors, however, in the long run it may prove more beneficial to students.

The use of computers and the Internet in the classroom is growing across universities all over the world. Use of the Internet in public school classrooms has increased from 35\% of schools in 1994 to $89 \%$ in 1998 (National Center for Educational Statistics [NCES] 1999) ${ }^{9}$. In a study conducted by Schumacher and Morahan-Martin $(2001)^{10}$, in 1990 over $80 \%$ of the students were enrolled in a class requiring the use of a computer. In 1997 this enrollment increased to 93\%. For this reason, it is imperative that research is conducted to determine if these same traits that need to be applied to instruction are needed on the World Wide Web. If using the computer and the Internet is a requirement of students, they are at a disadvantage if the programs, software, and sites used are not appealing to their learning styles.

In sum, this study explored issues related to information literacy. Engineering educators should incorporate pedagogy to support acquisition of information search skills within their courses, since these skills are difficult to acquire without instruction and guidance. This study demonstrated an association between a common behavioral trait, Type A, and information search success indicating that Type A participants were less successful in their information searches. Given that Type A students are highly reliant on structure and control, more likely to experience self-imposed time pressure, are easily frustrated by delays, and tend to rush through material or activities, it is important to increase awareness among educators who can observe these tendencies and alter their instructional methods to accommodate students so that cognitive processing styles do not undermine the development of information literacy. Several recommended practices to support the development of information literacy for engineering students adjusted for Type A tendencies are summarized in Table 1.

"Proceedings of the 2003 American Society for Engineering Education Annual Conference \& Exposition Copyright (c) 2003, American Society for Engineering Education" 
Table 1. Suggestions for Information Literacy Instruction of Type A Engineering Students

\begin{tabular}{|c|c|c|}
\hline Recommended Practice & Justification & Source \\
\hline $\begin{array}{l}\text { Emphasize search } \\
\text { process and help } \\
\text { students attend to the } \\
\text { process of searching, } \\
\text { rather than the output }\end{array}$ & $\begin{array}{l}\text { Type A students tend to be strongly goal } \\
\text { oriented and may not attend to } \\
\text { information paths, search terms, output } \\
\text { values and other attributes of the search } \\
\text { process. }\end{array}$ & $\begin{array}{l}\text { Bingham and Haley } \\
(1989)^{11}\end{array}$ \\
\hline $\begin{array}{l}\text { Help students } \\
\text { understand the non- } \\
\text { linearity of Web-based } \\
\text { searches and show } \\
\text { students how non-linear } \\
\text { searches can be } \\
\text { productive }\end{array}$ & $\begin{array}{l}\text { Type A students are highly structured, } \\
\text { and become frustrated in environments } \\
\text { they perceive to be disorganized. The } \\
\text { resulting stress can undermine their } \\
\text { performance. }\end{array}$ & $\begin{array}{l}\text { Lee, Ashford, and Jamieson } \\
(1993)^{12}\end{array}$ \\
\hline $\begin{array}{l}\text { Emphasize feedback } \\
\text { mechanisms that are } \\
\text { located on search } \\
\text { interfaces }\end{array}$ & $\begin{array}{l}\text { Since Type A students tend to be very } \\
\text { time conscious and goal oriented, it is } \\
\text { important to direct their attention to } \\
\text { feedback bars that give an indication of } \\
\text { progress. }\end{array}$ & Jamal and Baba $(2001)^{13}$ \\
\hline $\begin{array}{l}\text { Assist students with } \\
\text { setting realistic time } \\
\text { goals for search sessions }\end{array}$ & $\begin{array}{l}\text { Type A students become easily } \\
\text { frustrated by delays (i.e., return of } \\
\text { results of searches, identifying relevant } \\
\text { search terms, etc.). The greater the } \\
\text { sense of time pressure (exacerbated by } \\
\text { setting unrealistic time goals) the poorer } \\
\text { the performance. }\end{array}$ & $\begin{array}{l}\text { Jamal and Baba }(2001)^{13} \text {; } \\
\text { Bingham and Haley } \\
(1989)^{11}\end{array}$ \\
\hline $\begin{array}{l}\text { Emphasize the } \\
\text { independence and non- } \\
\text { competitiveness of } \\
\text { information searches and } \\
\text { the importance of self- } \\
\text { paced learning }\end{array}$ & $\begin{array}{l}\text { Type A students can become more } \\
\text { driven and competitive in situations in } \\
\text { which evaluation is emphasized and this } \\
\text { added "evaluation discomfort" could } \\
\text { undermine their progress. }\end{array}$ & $\begin{array}{l}\text { Muntaner, Llorente, } \\
\text { Nagoshi (1989) }\end{array}$ \\
\hline
\end{tabular}

In order to ensure that these data are an accurate representation of college students, further study should be conducted to examine differences across majors and universities. Participants were specifically selected from the Industrial Engineering Department because only one major could be examined. Using students from several majors would prove difficult when developing a list of questions of familiar subject matter. The study was conducted during the summer; therefore the students from which to choose may not have been an accurate representation of the entire Industrial and Systems Engineering Department or Engineering students in general. Limitations also include restriction of range due to the time of year that the study was conducted. 


\section{References}

1. Friedman, M. and Rosenman, R. F. (1974). The Type A behavior and your heart. New York: Knopf.

2. Lenox, M. F. and Walker, M. L. (1993) Information literacy in the educational process. The Educational Forum, 57(2), 312-324.

3. Maddux, C. D., Johnson, D. L. and Willis, J. W. (1997). Educational computing, learning with tomorrow's technologies $\left(2^{\text {nd }}\right.$ ed.). Needham Height, MA: Allyn \& Bacon.

4. Amichai-Hamburger, Y. (2002). Internet and personality. Computers in Human Behavior, 18, 1-10.

5. Jenkins, C. D. Ph.D., Zyzanski, S. J. Ph.D. and Rosenman, R. H. M.D. (1979). Jenkins Activity Survey. JAS Manual, C, 1-31.

6. Kliewer, W., Lepore, S. J. and Evans, G. W. (1990). The Costs of Type B Behavior: Females at Risk in Achievement Situations. Journal of Applied Social Psychology, 20(16), 1369-1382.

7. Perry, R. P. and Tunna, K. (1988). Perceived Control, Type A/B Behavior, and Quality of Instruction. Journal of Educational Psychology, 80(1), 102-110.

8. Andersen, D. K. and Reed, W. M. (1998). The Effects of Internet Instruction, Prior Computer Experience, and Learning Style on Teachers' Internet Attitudes and Knowledge. Journal of Educational Computing Research, 19(3), 227-246.

9. National Center for Educational Statistics [NCES] (1999, June 1999) Condition of Education. [Online]. Available: http://www.nces.ed.gov/pubsinfo.asp?pubid=199902.

10. Schumacher, P. and Morahan-Martin, J. (2001). Gender, Internet and computer attitudes and experiences. Computers in Human Behavior, 17, 95-110.

11. Bingham, D. and Hailey, B. J. (1989). The time-urgency component of the Type A behavior pattern: Time pressure and performance. Journal of Applied Social Psychology. 19(5), 425-432.

12. Lee, C., Ashford, S. J., and Jamieson, L. F. (1993). The Effects of Type A behavior dimensions and optimism on coping strategy, health, and performance. Journal of Organizational Behavior, 14(2), 143-157.

13. Jamal, M. and Baba, V. V. ( 2001). Type-A behavior, job performance, and well-being in college teachers. International Journal of Stress Management, 8(3), 231-240.

14. Muntaner, C., Llorente, M., and Nagoshi, C. (1989). Evaluative instructions and interpersonal aggression in the Type A behavior pattern. Aggressive Behavior, 15(2), 161-170.

\section{Biography}

\section{CHANEL THOMAS}

Chanel Thomas is a senior in Industrial and Systems Engineering at Virginia Polytechnic Institute and State University pursuing graduate study in the area of Human Factors. She is a member of the Ronald E. McNair Scholars Program as well as the College of Engineering Dean's Team.

\section{CHANG SOO NAM}

Chang S. Nam is a doctoral candidate in the Grado Department of Industrial and Systems Engineering at Virginia Polytechnic Institute and State University, Blacksburg, VA. He received his M.S. in Industrial Engineering from State University of New York, Buffalo in 2000.TONYA SMITH-JACKSON

\section{TONYA L. SMITH-JACKSON}

Tonya L. Smith-Jackson, Ph.D. is an assistant professor of Human Factors Engineering in the Grado Department of Industrial and Systems Engineering. For the past 12 years, she has conducted research in the cognitive ergonomics. 